Revista de Investigación Educativa 28

enero-junio, 2019 | ISSN 1870-5308 | Xalapa, Veracruz

Instituto de Investigaciones en Educación | Universidad Veracruzana

\title{
Una agenda intercultural para la educación nacional
}

Stefano Sartorello

DOI: https://doi.org/10.25009/cpue.v0i28.2596

T a importancia de volver a impulsar la Educación Intercultural Bilingüe (EIB) para Ltodos en el Sistema Educativo Nacional (SEN) de México está claramente destacada en el documento "Una agenda intercultural para la educación nacional", ${ }_{1}^{1}$ documento elaborado por un grupo plural y diverso de investigadores educativos, ${ }^{2}$ que ha sido entregado en manos del nuevo Secretario de Educación con el fin de incidir en la formulación de las políticas educativas que implementará el gobierno encabezado por Andrés Manuel López Obrador. Durante poco más de un año, los investigadores que firmamos este documento nos reunimos para analizar avances y retrocesos que la EIB ha tenido a lo largo de las tres últimas décadas en un país como el nuestro que, desde

1. http://inide.ibero.mx/agenda-intercultural-para-la-educacion-nacional/

2. Alejandro Martínez Canales, Ana Elena Erape Baltazar, Ana Laura Gallardo Gutiérrez, Elizabeth Martínez Buenabab, Fernando Salmerón Castro, Guadalupe Mendoza Zuany, Gunther Dietz, Juan Ignacio Hernández Vasquez, Lourdes Casillas Muñoz, Luz Ma. Moreno Medrano, Lydia Raesfeld, María Bertely Busquets, Marisol Silva Laya, Paola Ortelli, Rebeca Barriga Villanueva, Rosa Elena Durán González, Sylvia Schmelkes del Valle, Verónica Kugel, Yesid Sierra Soler.

\footnotetext{
a Doctor en educación. Profesor-Investigador, Instituto de Investigaciones para el Desarrollo de

la Educación, Universidad Iberoamericana de la Ciudad de México, México.

凶stepol2000@yahoo.com
} 
1992, se reconoce pluricultural en su Constitución, pero que en la realidad cotidiana que se vive en las escuelas y afuera de ellas, sigue siendo discriminador y racista con los pueblos indígenas y afromexicanos que lo habitan. A partir de una extensa revisión de los hallazgos reportados por las investigaciones educativas realizadas en nuestro país, y luego de sendas discusiones y amplios debates sustentados en nuestras respectivas experiencias de investigación e intervención educativa, logramos identificar seis campos prioritarios de acción para interculturalizar el SEN.

1. Estado, normatividad y políticas, donde se argumenta la importancia de fomentar la construcción de políticas públicas "desde abajo", escuchando e integrando a todos los actores diversos implicados, especialmente a los pueblos indígenas y afromexicanos. También se destaca la apremiante necesidad de asumir que las políticas de atención a la diversidad son para todos y no sólo para los pueblos indígenas, que son políticas diferenciadas que deben regir la relación entre el Estado y los pueblos y grupos sociales, culturales o lingüísticos diferenciados. Por ello proponemos revisar los indicadores educativos que miden el logro y la calidad educativa, para que éstos den cuenta de la riqueza de los pueblos indígenas y afromexicanos y de sus formas de aprender y ver el mundo, y para que no se sigan imponiendo criterios educativos homogeneizantes a través de las pruebas estandarizadas.

2. Enfoques teóricos, epistemológicos y metodológicos sobre EIB, en el que se aboga a favor de una real valoración y dignificación de las lenguas y culturas indígenas en el ámbito educativo formal, lo que implica superar los planteamientos en pro de una educación inclusiva para la población indígena que, al ser considerada un sector vulnerable de la población nacional, tiende a desvalorar y victimizar a los estudiantes, sus lenguas y culturas desde una visión de déficit sociocultural, lingüístico y educativo. Lo anterior pasa inevitablemente por fomentar la participación de las comunidades, organizaciones, movimientos y pueblos indígenas y afromexicanos en la investigación, diseño, implementación, seguimiento y evaluación de los procesos, programas y materiales educativos destinados a ellos y al conjunto de la población nacional, con el fin de contribuir a eliminar el racismo estructural y la discriminación que caracteriza las relaciones entre la sociedad nacional y los pueblos indígenas. También se considera prioritario promover la flexibilización y diversificación curricular, con el fin de adecuar la oferta educativa en todos los niveles educativos a las características socioculturales y lingüísticas de la población indígena y afromexicana.

3. El bilingüismo como tema prioritario en las políticas lingüísticas y educativas, en el cual se afirma la importancia de revisar a fondo las políticas lingüísticas y educativas 
vigentes y abrirlas a la participación de las poblaciones indígenas; sensibilizar de manera consistente y práctica la presencia indígena en toda la República y la diversidad lingüística y étnica que ello implica; y aumentar los materiales didácticos de apoyo y propiciar el uso de las lenguas originarias en diferentes ámbitos de uso, donde predomina mayoritariamente el español.

4. Formación de docentes e investigadores para la EIB, donde se argumenta la necesidad de integrar equipos de profesionales e investigadores indígenas y no indígenas para fortalecer y re-construir las instituciones y las propuestas de formación inicial y continua de docentes para el medio indígena que consideren el derecho a la educación de los pueblos basada en sus procesos de decisión, saberes y expectativas de vida. Recuperar los recursos humanos — profesionistas e investigadores - que se han formado en el campo de la educación indígena, la educación intercultural y en el de la atención a la diversidad sociocultural y lingüística, para fortalecer y trabajar en propuestas de formación de docentes para la educación básica general que contemple el tema de la diversidad y la diferencia con sentido de equidad y derecho. Impulsar trabajos en equipos de docentes, especialistas, padres de familia y agentes educativos vinculados a la educación escolar indígena, que contribuyan a redefinir modelos de evaluación de los aprendizajes escolares de y los niños y jóvenes indígenas en perspectivas que reconozcan diversas formas de aprender y habilidades de diversos tipos.

5. Interculturalidad en básica y media superior, en el que se propone ampliar la estrategia educativa intercultural en zonas urbanas y metropolitanas, de tal manera que el profesor o profesora bilingüe (español-lengua vernácula) trascienda su papel como intermediario-traductor. Considerar la situación sociocultural de desigualdad que condiciona la formación escolarizada de los estudiantes, la cual debe ser un punto de partida para fundar una estrategia de reconocimiento y respeto distinta a la culturalista. Retomar experiencias y proyectos educativos de corte crítico, la mayoría no escolarizados, para el enriquecimiento y contextualización del sistema educativo y de su propuesta intercultural.

6. Interculturalidad en la educación superior, campo en el cual las propuestas de acción abarcan tanto a las universidades convencionales como a las universidades interculturales. En cuanto a las primeras, se propone posicionar en las agendas institucionales y de políticas de educación superior la necesidad de reconocer la diversidad del estudiantado de las universidades convencionales a través de acciones concretas y coordinadas con enfoque de derechos. Generar un diálogo interinstitucional y al interior de cada universidad para construir espacios formativos que den cabida al 
pluralismo epistemológico y lingüístico en las diversas disciplinas. Con respecto de las universidades interculturales, se propone otorgar autonomía universitaria a las universidades interculturales, para academizar sus procesos y órganos de toma de decisiones, fortaleciendo la vida colegiada bajo el principio de respeto a los aportes epistémicos en un plano de igualdad. Redefinir la participación de la Secretaría de Educación Pública (SEP) y de los gobiernos estatales para que vigilen la calidad de los procesos formativos y que democraticen el espacio de toma de decisiones del desarrollo académico institucional, evitando intervenir como piezas/actores dominantes de sus Consejos directivos, ya que hasta la fecha excluyen por completo la participación de académicos y de estudiantes. Crear nuevas universidades interculturales en regiones que carecen de esta oferta educativa, como por ejemplo en Oaxaca, Yucatán y Campeche, privilegiando criterios de pertinencia social y académica, que desplacen presiones de grupos de poder. Consolidar y ampliar la financiación compartida entre la federación y las entidades federativas a las universidades interculturales, para que puedan profundizar sus procesos de fortalecimiento y su autonomía; invertir en aspectos clave de la operación de las universidades interculturales, como por ejemplo la infraestructura básica de bibliotecas, Internet, laboratorios, comedores y dormitorios (teniendo en cuenta la procedencia socioeconómica de la gran mayoría de sus estudiantes). Diseñar e implementar programas específicos de basificación de sus docentes como Profesores de Tiempo Completo (PTC), dándoles acceso en términos equitativos a los fondos federales de SEP-PRODEP, de CONACYT, SNI, etc., e integrando a las universidades interculturales en términos equitativos en la atención que todas las Instituciones de Educación Superior reciben por la Secretaría de Educación Superior de la SEP, para así poner fin a la discriminación institucional de las universidades interculturales.

\section{Una educación para la interculturalidad}

Nuestros análisis y relativas propuestas coinciden en destacar la apremiante necesidad de interculturalizar las políticas y prácticas educativas de todos los niveles y modalidades educativas del SEN, para que en las escuelas, colegios y universidades donde estudian los niños y jóvenes mexicanos que habitarán el México del futuro, se enseñe y se aprenda a valorar la diversidad sociocultural y lingüística que caracteriza nuestra hermosa nación. Estamos convencidos de que la diversidad que caracteriza a 
la sociedad mexicana contemporánea no puede ni debe seguir siendo percibida por el sistema educativo nacional como un problema o como un obstáculo. La diversidad cultural, étnica, lingüística, de género, de identidad sexual, de cosmovisiones y religiones, de edades y de clases sociales es una característica inherente a toda sociedad contemporánea. El SEN tiene que aprender a aprovechar la diversidad como un recurso de aprendizaje, como un método de enseñanza y como un enfoque transversal que deberá atravesar todos los niveles, modalidades y subsistemas, todas las edades y regiones atendidas por la educación pública mexicana. 